\title{
Oxygen Adsorption, Subsurface Oxygen Layer Formation and Reaction with Hydrogen on Surfaces of a Pt-Rh Alloy Nanocrystal
}

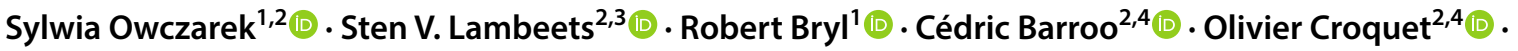 \\ Leszek Markowski ${ }^{1}$ (1) . Thierry Visart de Bocarmé ${ }^{2,4}$ (1)
}

Accepted: 15 October 2020 / Published online: 29 October 2020

(c) The Author(s) 2020

\begin{abstract}
The oxygen adsorption and its catalytic reaction with hydrogen on Pt-Rh single crystals were studied at the nanoscale by Field Emission Microscopy (FEM) and Field Ion Microscopy (FIM) techniques at $700 \mathrm{~K}$. Both FEM and FIM use samples prepared as sharp tips, apexes of which mimic a single nanoparticle of catalyst considering their similar size and morphology. Oxygen adsorption on Pt-17.4 at.\%Rh samples leads to the formation of subsurface oxygen, which is manifested in the field emission (FE) patterns: for $\mathrm{O}_{2}$ exposure of $\sim 3$ Langmuir (L), $\{113\}$ planes appear bright in the emission pattern, while for higher oxygen doses, i.e. $84 \mathrm{~L}$, the bright regions correspond to the high index planes between the $\{012\}$ and $\{011\}$ planes. Formation of subsurface oxygen is probably accompanied by a surface reconstruction of the nanocrystal. The subsurface oxygen can be effectively reacted off by subsequent exposure of the sample to hydrogen gas at $700 \mathrm{~K}$. The hydrogenation reaction was observed as a sudden, eruptive change of the brightness seen on the FE pattern. This reaction resulted in the recovery of the initial field emission pattern characteristic of a clean tip, with $\{012\}$ facets being the most visible. It was shown that the oxygen accumulation-reduction process is completely reversible. The obtained results indicate that the presence of subsurface species must be considered in the description of reactive processes on $\mathrm{Pt}-\mathrm{Rh}$ catalysts.
\end{abstract}

Keywords Field emission microscopy $\cdot$ FEM $\cdot$ Nanocatalysis $\cdot \mathrm{Pt} \cdot \mathrm{Rh} \cdot$ Subsurface oxygen $\cdot$ Model catalysis

\section{Introduction}

The rapid development of chemical industries and oil refineries has necessitated the use of advanced catalytic materials with activity, selectivity and durability compatible with economic viability. Nowadays, major industrial issues focus

Sylwia Owczarek

sylwiab@ifd.uni.wroc.pl

$\bowtie$ Robert Bryl

rbryl@ifd.uni.wroc.pl

1 Institute of Experimental Physics, University of Wrocław, Wrocław, Poland

2 Chemistry of Surfaces, Interfaces \& Nanomaterials, Faculty of Sciences - CP-243, Université libre de Bruxelles, Brussels, Belgium

3 Environmental Molecular Sciences Laboratory, Pacific Northwest National Laboratory, Richland, WA, USA

4 Interdisciplinary Center for Nonlinear Phenomena and Complex Systems (CENOLI), Université libre de Bruxelles, Brussels, Belgium on the abatement of pollutants for which new and optimized catalysts will continue to play an important role. Platinum group metals (PGMs), comprising Pt, $\mathrm{Rh}$ and Pd are widely used for catalytic processes. Each metal of this group possesses a high catalytic reactivity for either oxidation or reduction reactions. However, to make the catalysts cheaper, more efficient and to ensure their acceptable performance, these elements are often combined as alloys. The interaction between two metals usually brings significant enhancement of their activity, selectivity and stability, as compared to the properties of single metals. Pt-based catalysts are widely used in industrial applications [1,2]. Pt-Rh alloys are an essential component of the "three-way catalysts", because of their outstanding capabilities to both selectively reduce nitrogen oxides $\left(\mathrm{NO}_{\mathrm{x}}\right)$ to nitrogen gas $\left(\mathrm{N}_{2}\right)$, and to oxidize $\mathrm{CO}$ and unburnt hydrocarbons into $\mathrm{CO}_{2}$ and $\mathrm{H}_{2} \mathrm{O}$ [3-6]. Moreover, this binary alloy is used as gauze catalyst in the Ostwald process to produce nitric acid: the first stage of this process is the catalytic oxidation of gaseous ammonia to nitric oxide [7, 8]. 
Application of cyclic oxidizing and reducing conditions to bimetallic alloys systems at high temperatures usually causes significant changes of their surface and bulk structure and composition, and also strongly influences their catalytic activity $[8,9]$. Previous studies on catalytic properties of $\mathrm{Pt}-\mathrm{Rh}$ with Auger Electron Spectroscopy (AES), X-Ray Photoelectron Spectroscopy (XPS), Scanning Tunneling Microscopy (STM) and Low-Energy Ion Scattering (LEIS) techniques have shown that, in vacuo, the surface becomes enriched with Pt at sufficiently high temperatures (> 873 K) [10-15]. On the contrary, oxygen-containing gases (such as $\mathrm{NO}, \mathrm{O}_{2}$ and $\mathrm{N}_{2} \mathrm{O}$ ) induce Rh segregation to the surface [16-19]. The extent of Rh enrichment strongly depends on thermal treatment applied, its duration and crystallographic orientation of the surface. Atom Probe Tomography (APT) studies revealed that at temperatures below $500 \mathrm{~K}$, Rh was drawn to the surface in nearly all regions of the alloy specimens [20, 21]. However, when temperature was raised above $573 \mathrm{~K}$, the Rh-enriched regions were distributed over Pt-Rh alloy nanoparticles. The Rh-rich top layers disappeared from certain specific planes: Rh-depletion was observed on $\{001\}$ and $\{012\}$ regions of $\mathrm{Pt}-\mathrm{Rh}$, whereas additional $\mathrm{Rh}$ enrichment was noted on $\{111\}$ planes. This dual behavior was explained by diffusion processes occurring normal and parallel to the local surface. This observation can have significant impact on the reaction dynamics [21]. For example, field emission microscopy (FEM) revealed oscillations under $\mathrm{NO}_{2}+\mathrm{H}_{2}$ reaction on a Pt-17.4 at.\% Rh alloy nanosized crystal at $425 \mathrm{~K}$, while for pure $\mathrm{Pt}$ and $\mathrm{Rh}$ the non-linear behavior was observed at $390 \mathrm{~K}$ and at $450 \mathrm{~K}$, respectively [22-24].

Pt-Rh alloys surface transformations induced by oxygenbased gases depend on the energy of adsorption of molecules or dissociated species, as well as on the surface energy of the metal. Based on known heats of oxide formation for various $\mathrm{Pt}$ and $\mathrm{Rh}$ oxides $\left(134 \mathrm{~kJ} \cdot \mathrm{mol}^{-1}\right.$ for $\mathrm{PtO}_{2}, 71 \mathrm{~kJ} \cdot \mathrm{mol}^{-1}$ for $\mathrm{PtO}[25,26]$ and $365-405 \mathrm{~kJ} \cdot \mathrm{mol}^{-1}$ for $\mathrm{Rh}_{2} \mathrm{O}_{3}$ [27]), one may assume that the adsorption energy of oxygen atoms on $\mathrm{Rh}$ is larger than on Pt surfaces. In the case of Rh-enriched samples, the surface becomes preferentially oxidized, and consequently, during this oxidation process, metallic $\mathrm{Rh}$ is continuously replaced with $\mathrm{RhO}_{\mathrm{x}}$ species. Oxygen species, either present as adsorbed species, subsurface oxygen or in oxide layers, may lead to important changes in the chemical nature of the surface and in the surface free energies. They can trigger surface reconstructions such as faceting. These modifications can in turn deeply affect the activity and/or selectivity of the catalysts.

Field Ion and Field Emission Microscopy (FIM and FEM) have been widely applied to imaging of quasi-hemispherical nanosized surfaces. They are well-suited for the study of catalytic properties of metallic alloys as functions of gas composition, temperature and local surface reactivity before, after and during the ongoing reactions. These techniques allow in operando measurements of the kinetics of the surface processes over specimens presenting various facets of different crystallographic orientations, with nanoscale or even atomic lateral resolution [28]. The size and shape of the sample closely approximate a single model nanoparticle of catalyst used in applied formulations of catalysts. In this paper, we present the results of $\mathrm{O}_{2}$ adsorption and its interaction with $\mathrm{H}_{2}$ on single nanosized Pt-17.4 at.\%Rh crystals at $700 \mathrm{~K}$. In our study, the video-FEM was used to follow dynamic structural changes at the various stages of the reaction by monitoring the brightness pattern in real time.

\section{Experimental}

Measurements were performed in a ultrahigh vacuum (UHV) system with a base pressure of $10^{-8} \mathrm{~Pa}$. The FIM and FEM system enabled the study of the surface processes occurring on a tip-shaped sample. The observed tip apex along with its gaseous environment can thus be seen as a nanoreactor to study different dynamical behaviors and to determine kinetic parameters [29]. FIM is based on the ionization of a gas (imaging gas) at the surface of the sample while the sample is positively charged as compared to the grounded detector screen. Once formed, ions are accelerated towards the screen where image formation is achieved. A magnification of approximately $10^{6}$ is typical, and atomic lateral resolution is usually obtained under cryogenic temperature [30]. FEM is based on the emission of electrons from the sample while the sample is negatively polarized as compared to the detector screen. At constant electric field and temperature, the field emission current density $\boldsymbol{J}$ depends on the field $\boldsymbol{F}$ distribution along the tip, but also on the local work function $\boldsymbol{\phi}$, following the Fowler-Nordheim equation [31].

$\boldsymbol{J}=\boldsymbol{a} \frac{\boldsymbol{F}^{\mathbf{2}}}{\phi} \exp \left(\frac{-\boldsymbol{b} \phi^{\mathbf{3} / \mathbf{2}}}{\boldsymbol{F}}\right)$

where $a, b$ are constant parameters.

For hemispherical tips, the FE patterns appear as a 2-dimensional map of the distribution of the local work function over the emitter surface. The work function depends on the nature of the material, on the crystallographic structure of the surface of interest, and on the presence of adsorbates and subsurface species $[32,33]$. Therefore, the monitoring of local brightness variations with time enables to follow the presence of adsorbate/subsurface species and their variations at the surface of the samples [34].

For the present study, Pt-Rh (82.6-17.4 at.\%) alloy was used as a model catalyst. The samples, prepared as very sharp tips with a radius curvature of few tens of $\mathrm{nm}$, were produced from high purity wire (Alfa-Aesar, diameter 
$0.127 \mathrm{~mm})$. First, the wire was electrochemically etched in a molten salt mixture of $\mathrm{NaCl}$ and $\mathrm{NaNO}_{3}(1: 4, w / w)$ at $\sim 520{ }^{\circ} \mathrm{C}$ with $2.0 \mathrm{~V}_{\mathrm{DC}}$. Afterwards, tips were subsequently cleaned and developed in situ by short cycles of thermal annealing and field evaporation to remove impurities, as well as to provide quasi-hemispherical shape of the apex. The shapes and morphologies of the tips were characterized with atomic-scale resolution by FIM, using $\mathrm{Ne}$ gas (purity $99.999 \%$, Praxair) as imaging gas at a pressure of $3 \times 10^{-3} \mathrm{~Pa}$, with samples held at $70 \mathrm{~K}$.

After FIM characterization at low temperature, oxygen and hydrogen gases (Messer, purity $99.998 \%$ and $99.999 \%$ respectively) were admitted into the microscope chamber through a high precision leak valve. The purity of the gases was measured using a quadrupole mass spectrometer. The adsorption and hydrogenation reactions were studied at $700 \mathrm{~K}$ using FEM technique at electric fields below $2.7 \mathrm{~V} /$ $\mathrm{nm}$ near the tip apex. Even though the lateral resolution of $2.5 \mathrm{~nm}$ [30] of FEM is lower as compared to FIM, FEM enables the observation of dynamic processes in real time, over several facets with different crystallographic orientations simultaneously. Additionally, both FEM and FIM require the presence of a high electric field to image the sample, but the field strength required in FEM is typically in the range of the electric field encountered in STM studies i.e. approximately ten times lower than in the FIM case. The influence of the electric field on the local chemistry is thus less dramatic in FEM studies [35]. Videos were acquired using a high-sensitivity camera (Panasonic Moonlight) at a frame rate of $50 \mathrm{fps}$ (frames per second). The dynamics of the process were analyzed by measuring the variations of gray levels in the emission patterns (corresponding to local changes of electron emission intensity) over time on specific regions of interests.

\section{Results}

\subsection{Pt-Rh Nanocrystal Characterization}

The first part of this section focuses on the characterization of the initial state of the $\mathrm{Pt}_{0.826} \mathrm{Rh}_{0.174}$ nanosized crystals by FIM and FEM. Figure 1 presents micrographs of the sample taken before the whole cycle of experiments with oxygen adsorption and hydrogenation. In Fig. 1a, we present a highresolution field ion (FI) micrograph of a clean and quasihemispherical tip sample imaged with neon gas at $70 \mathrm{~K}$. The micrograph enables for identification of multiple facets with different crystallographic orientations located along the various zone lines between the topmost (113) pole and the peripheral planes. Both $\mathrm{Pt}$ and $\mathrm{Rh}$ are face-centered cubic (fcc) crystals, although with $3.2 \%$ lattice constants mismatch $(0.392 \mathrm{~nm}$ and $0.380 \mathrm{~nm}$, respectively). The average radius of the of curvature of the quasi-hemispherical specimen apex shown in Fig. 1a was around $22 \mathrm{~nm}$. This value was estimated by the standard procedure of net counting of the number of atomic layers between two facets of known crystallographic orientations in the field ion micrograph [30], the values obtained for different crystallographic directions where then averaged.

Figure $1 \mathrm{~b}$ presents the same Pt-Rh tip imaged by FEM at $70 \mathrm{~K}$. The brightest spots in the pattern correspond to $\{012\}$ planes, whereas the regions of the pattern corresponding to other low-index planes, i.e. $\{001\},\{111\},\{011\}$ and $\{113\}$ are dark. It is explained by the lowest work function values for pure $\mathrm{Rh}(012)$ and $\mathrm{Pt}(012)$ surfaces $(4.64 \mathrm{eV}$ and $5.18 \mathrm{eV}$, respectively) in comparison to other low index planes; i.e. $\mathrm{Rh}(001)-5.38 \mathrm{eV}, \mathrm{Rh}(011)-4.77 \mathrm{eV}, \mathrm{Rh}(111)-4.95 \mathrm{eV}$, $\mathrm{Pt}(001)$ - $5.82 \mathrm{eV}, \operatorname{Pt}(011)-5.24 \mathrm{eV}, \operatorname{Pt}(111)-5.90 \mathrm{eV}$ $[32,36]$.

We notice that during repeated cycles of experiments carried out at $700 \mathrm{~K}$ the specimen apex showed a well-known
Fig. 1 Characterization of a (113)-oriented Pt-17.4 at.\%Rh tip: (a) Atomically resolved image obtained by Field Ion Microscopy with some main Miller indexes (imaging conditions: $F=38 \mathrm{~V} \cdot \mathrm{nm}^{-1}$, $\left.P_{\mathrm{Ne}}=2.5 \cdot 10^{-3} \mathrm{~Pa}, T=70 \mathrm{~K}\right)$. (b) Field Emission Microscopy image of the same sample, with a lower resolution. $\{012\}$ planes are visible due to their lower work function (imaging conditions: $F=3.7 \mathrm{~V} \cdot \mathrm{nm}^{-1}, T=70 \mathrm{~K}$, UHV conditions)
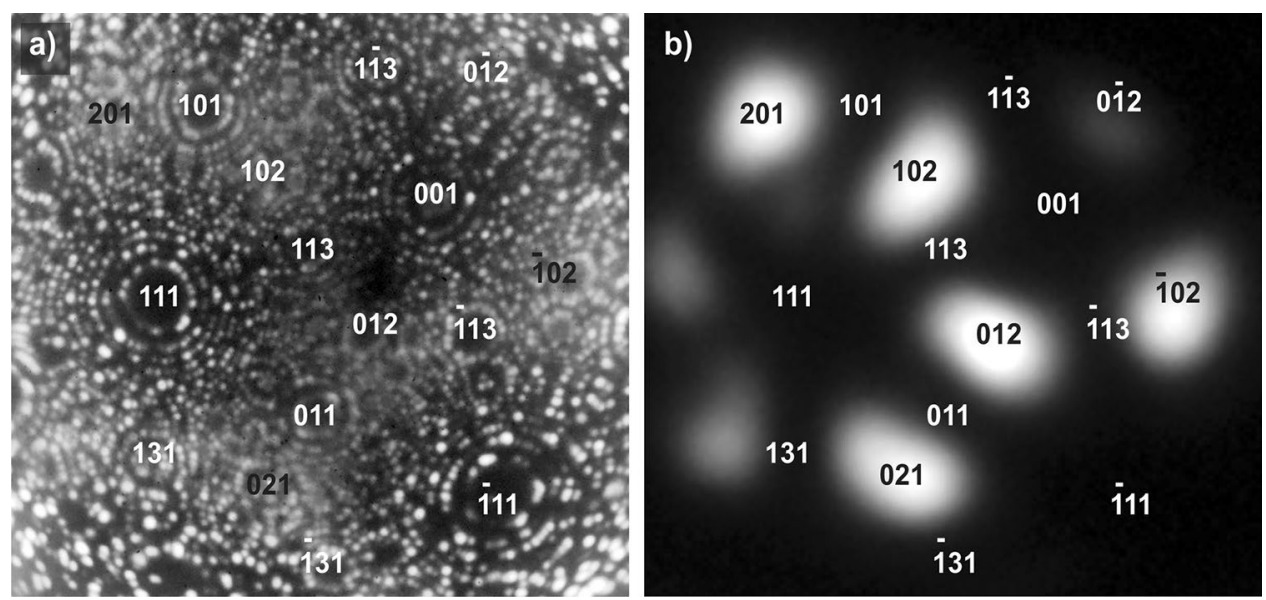
trend to blunt, making high resolution FIM imaging impossible because of the necessary voltage beyond the specifications of our microscope. For this reason, we cannot present FIM patterns showing the sample just before and after the experiments described below. For lower temperatures the reproducibility of the observations described below was significantly worse.

\subsection{Oxygen Adsorption on Pt-Rh Alloy Nanoparticles}

Prior to reduction reactions, the Pt-Rh nanocrystal was exposed to pure oxygen at $700 \mathrm{~K}$ and in the presence of electric field to enable monitoring of the adsorption process in real time. For the adsorbent-free specimen, presented in Fig. 2a, the $\{012\}$ planes are brighter due to their lower work function as compared to other planes. Afterwards, the tip was exposed to a constant flow of $\mathrm{O}_{2}$ gas at the pressure of $1.7 \times 10^{-5} \mathrm{~Pa}$, which caused the FE pattern evolution depicted in Fig. 2b-e. After the first few seconds (11 s, in
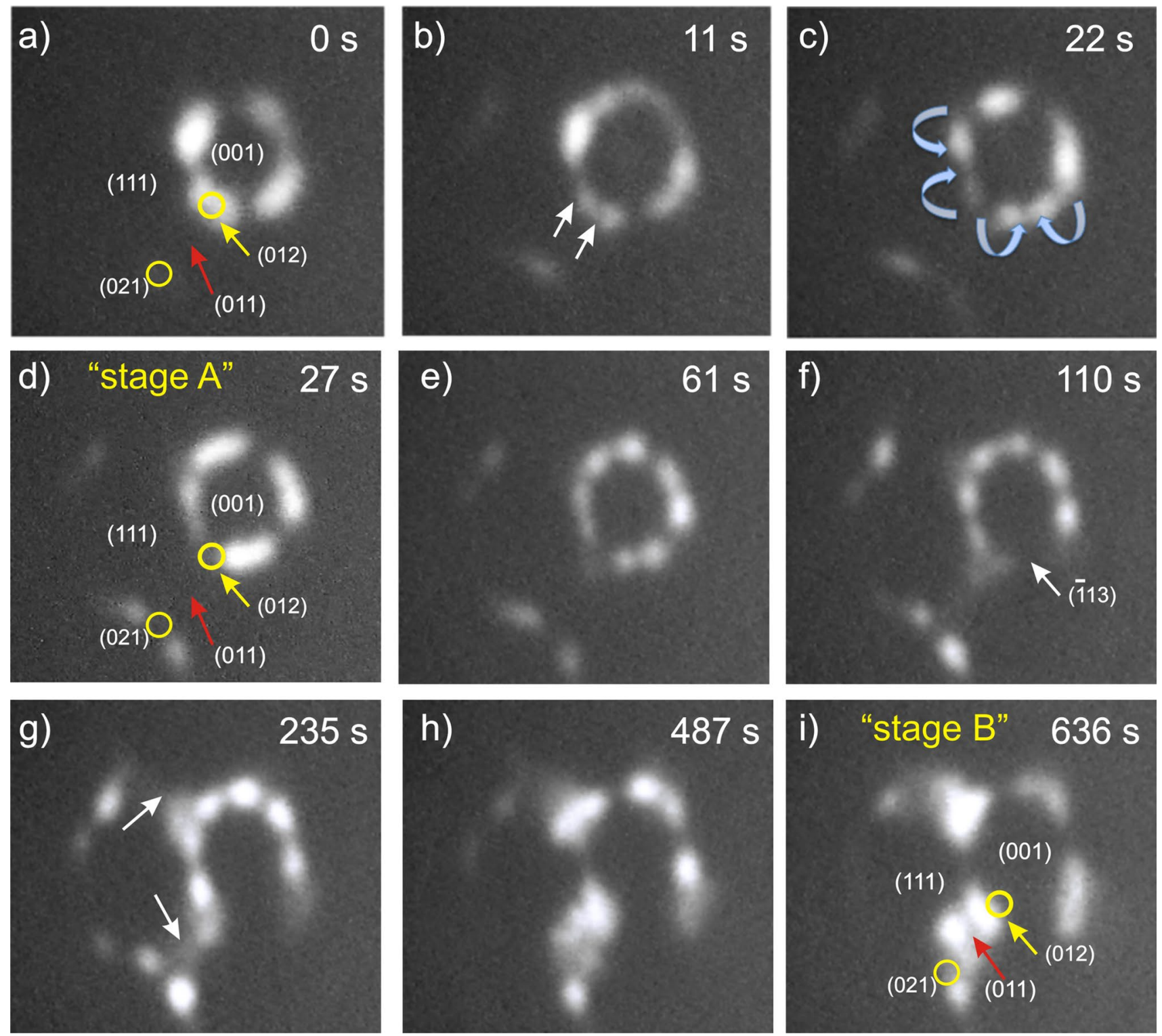

Fig. 2 Sequence of FE patterns of Pt-Rh tip (a) before and (b-d) during exposure to oxygen $\mathrm{P}_{\mathrm{O} 2}=1.7 \cdot 10^{-5} \mathrm{~Pa}$ at $700 \mathrm{~K}$ (imaging conditions: $\left.\mathrm{F}=2.0 \mathrm{~V} \cdot \mathrm{nm}^{-1}\right)$. The $\{012\}$ planes split into two smaller regions and merge into $\{113\}$ planes. The pattern in panel (d) refers to the "stage A" of the sample. The images (e-h) represent changes of the FE pattern during steady flow of the gas (imaging conditions: $\mathrm{F}=2.3 \mathrm{~V} \mathrm{~nm}^{-\mathbf{1}}$ ). The pattern in panel (i) refers to the "stage B" of the sample 
the case presented in Fig. 2), the original FE pattern slightly changed and a bright circle around the central (001) plane was formed (Fig. 2b). We mention that the $\{012\}$ planes split into two smaller bright spots indicated by the white arrows in Fig. 2b. With a constant flow of oxygen, the distance between these spots increased over time causing the fade-out of the $\{012\}$ facets, accordingly. The bright areas resulting from this splitting and corresponding to neighboring planes, i.e. (012) and (102) as well as (012) and (102), merged (Fig. 2c), as marked by blue arrows. They formed bright elongated regions located on $\{113\}$ planes after $27 \mathrm{~s}$, as shown in Fig. 2d. We will refer to this stage of FE pattern evolution as to "stage A" of the sample. With the sample still exposed to oxygen for longer time, the bright $\{113\}$ spots, located around (001) pole, split into two small bright regions, and the total brightness of the emission pattern decreased noticeably, as presented in Fig. 2e. This pattern and the next ones were taken at an electric field increased by about $0.3 \mathrm{~V} \cdot \mathrm{nm}^{-1}$, to partly compensate the overall darkening of FEM images. The dark gaps in the centers of $\{113\}$ regions spread out over time and remain visible in further micrographs (Fig. 2f-i). After approximately $235 \mathrm{~s}$ of oxygen exposure, bright areas, indicated by arrows in Fig. $2 \mathrm{~g}$, appeared around a peripheral (111) plane. The brightest regions expand towards $\{011\}$ planes and, interestingly, the latter do not reach $\{012\}$ or $\{011\}$ planes but surround them. Figure $2 \mathrm{~h}$ presents the resulting FE pattern of the $\mathrm{Pt}-\mathrm{Rh}$ sample with dark $\{113\}$ planes and bright areas between $\{012\}$ and $\{011\}$ planes. We will refer to this FE pattern as to "stage B" of the sample.

To get a better insight into the observed phenomena, the same methodology was applied for experiments at various gas pressures from $9.5 \times 10^{-6} \mathrm{~Pa}$ to $7.0 \times 10^{-4} \mathrm{~Pa}$ at $700 \mathrm{~K}$. At low oxygen pressure $\left(\sim 10^{-5} \mathrm{~Pa}\right)$ the appearance of the "stage A" and its evolution to the "stage B" is clearly visible. While the pressure of reactive gas increased, the initial pattern corresponding to the clean surface transformed extremely fast to the final stage ("B") making the metastable "stage A" hardly observable. There is a correlation between the pressure $\boldsymbol{p}$ of oxygen and the time $\boldsymbol{t}$ in which the FE pattern evolved towards "stage A" and "stage B". In Fig. 3 the $\boldsymbol{t}$ is plotted versus the inverse of the gas pressure $1 / p$. As the exposure (or dosage) $\boldsymbol{d}$ to a surface is defined by multiplying the pressure of the gas by the time of exposure; $\boldsymbol{d}=\boldsymbol{t} \boldsymbol{p}$, the slopes of those lines correspond to oxygen dose $\boldsymbol{d}$ and can be calculated from:

$t=d \cdot \frac{1}{p}$

In accordance with Eq. (2), the dose of $3.0 \pm 0.5 \mathrm{~L}$ ( $1 \mathrm{~L}=1$ Langmuir $=1 \mathrm{~s} \cdot 1 \times 10^{-6}$ Torr $\left.\approx 1.3 \times 10^{-4} \mathrm{~Pa} \cdot \mathrm{s}\right)$ is

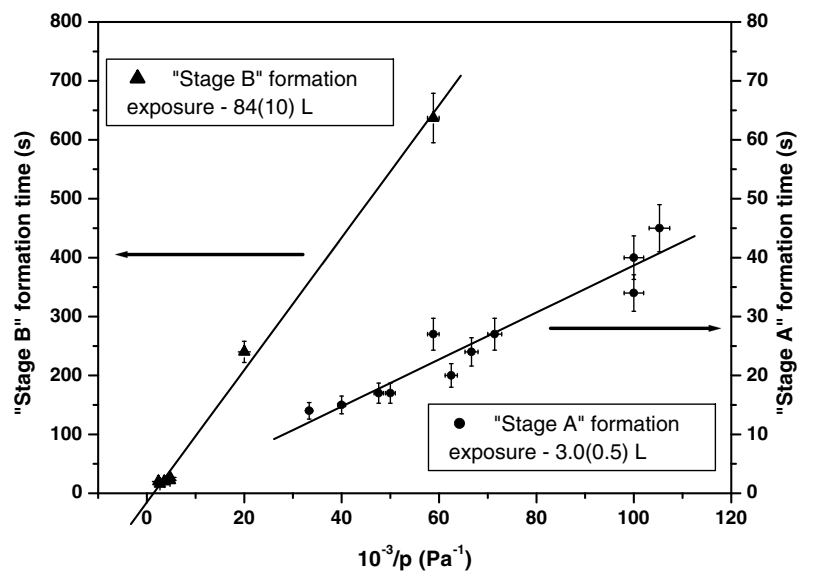

Fig. 3 Inverse $\mathrm{O}_{2}$ pressure dependence on the duration to develop "stage A" and "stage B". The value of exposure is calculated from the slope of the linear plot, and are $3.0 \pm 0.5 \mathrm{~L}$ and $84 \pm 10 \mathrm{~L}$ for "stage A" and "stage B", respectively

necessary for transformation of the FE pattern to "stage A", while to form the "stage B" a much higher oxygen exposure of $84 \pm 10 \mathrm{~L}$ is required.

\section{3 $\mathrm{O}_{2}+\mathrm{H}_{2}$ Reaction on the Pt-Rh Surface}

The results presented above reveal two stages of the oxidation of Pt-Rh sample, which may have a significant impact on the catalytic reactivity of the nanoparticles. Depending on the structural geometry and chemical composition, especially related to the formed oxide species, the reaction dynamics and the global catalytic activity may differ significantly. In this section, we demonstrate the results of $\mathrm{O}_{2}$ hydrogenation over Pt-Rh samples and describe the differences of behavior of sample at "stage A" and "stage B" during reaction.

Hydrogen gas was introduced into the analysis chamber after the occurrence of oxygen-induced FE pattern corresponding to chosen state ("A" or "B") of the sample, with the oxygen gas pressure kept constant. The Pt-Rh samples were exposed to $\mathrm{O}_{2}$ and $\mathrm{H}_{2}$ at various $\mathrm{H}_{2} / \mathrm{O}_{2}$ pressure ratios (from 7 to 20) corresponding to hydrogen-rich conditions. The sequence of images in Fig. 4 represents snapshots of FE patterns taken during the catalytic hydrogenation of $\mathrm{O}_{2}$ under reactive reducing conditions with $P_{\mathrm{O} 2}=1.4 \times 10^{-5} \mathrm{~Pa}$, $P_{\mathrm{H} 2}=1.9 \times 10^{-4} \mathrm{~Pa}$, at $T=700 \mathrm{~K}$. The initial stage of the tip corresponding to the "stage A" is seen in Fig. 4a. The hydrogen gas provoked a rapid increase of the pattern brightness initiated at $\{113\}$ planes, which is attributed to the violent reaction between $\mathrm{H}_{(\mathrm{ads})}$ and $\mathrm{O}_{(\mathrm{ads})}$ species. More specifically, initially, the (113) bright spots split into the bright small regions forming a ring around the (001) pole, as seen in Fig. 4b. After a few seconds, rapid and very intense ("explosive") increase in brightness of the ring was 

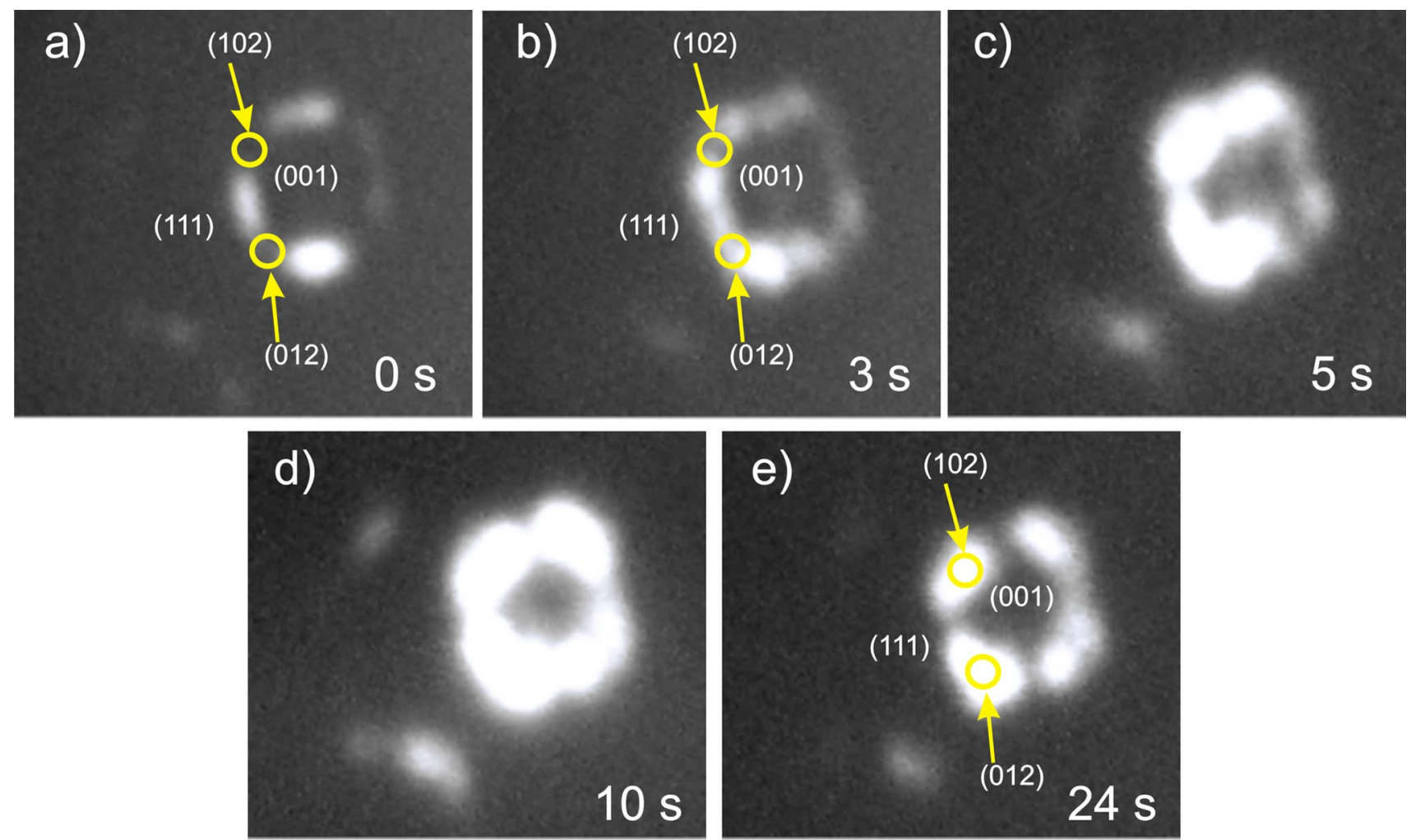

Fig. 4 FE patterns of the Pt-Rh nanocrystal before and during $\mathrm{O}_{2}-\mathrm{H}_{2}$ reaction. (a) Field emission micrograph taken before reaction. (b-e) Sequence of micrographs illustrating different stages dur-

observed (Fig. 4c, note that the pattern is taken at the same voltage as Fig. 4b), which then was extended towards the $\{012\}$ facets (Fig. 4d, e). As seen in Fig. 4e, the final FE pattern during reaction is identical to that of the clean tip. It remained unchanged as long as the sample was exposed to both gases at abovementioned partial pressures. At this stage, the brightest $\{012\}$ facets dominate over all others. Here, if the hydrogen flow was stopped, the formation of "stage A" followed the process described in the previous section (Fig. 2).

The $\mathrm{O}_{2}$ hydrogenation on $\mathrm{Pt}-\mathrm{Rh}$ sample starting from "stage B" is depicted in Fig. 5. Presented FE micrographs were taken during the reaction with following parameters: $P_{\mathrm{O} 2}=3.7 \times 10^{-4} \mathrm{~Pa} ; P_{\mathrm{H} 2}=3.0 \times 10^{-3} \mathrm{~Pa} ; \mathrm{T}=700 \mathrm{~K}$. The reaction ignited $9 \mathrm{~s}$ after the exposure to $\mathrm{H}_{2}$ in a quasi-concerted manner on regions located between the $\{012\}$ and $\{011\}$ planes, and subsequently spilled onto all $\{012\}$ facets (see Fig. 5b). The "explosive" brightening of the emission pattern was observed after about $22 \mathrm{~s}$ (Fig. 5c). The stage of local high reactivity (corresponding to the high brightness of the FE pattern) was maintained for about $20 \mathrm{~s}$. Afterwards, the brightness slightly decreased revealing a field emission pattern which bears a strong resemblance to that of the clean Pt-Rh tip (Fig. 2a) (note that the field strength ing reaction after $\mathrm{H}_{2}$ addition. Experimental conditions: $T=700 \mathrm{~K}$, $P_{\mathrm{O} 2}=1.4 \times 10^{-5} \mathrm{~Pa}, P_{\mathrm{H} 2}=1.9 \times 10^{-4} \mathrm{~Pa}, F=2.1 \mathrm{~V} \cdot \mathrm{nm}^{-1}$

in case of Fig. $5 \mathrm{~d}-2.3 \mathrm{~V} \cdot \mathrm{nm}^{-1}$ - is higher than for Fig. 2a $-2.0 \mathrm{~V} \cdot \mathrm{nm}^{-1}$, as the FE pattern for "stage B" was observed at elevated field). As long as the hydrogen was present in the chamber under reaction conditions, the system remained stable at high electric fields. The additional oxygen adsorption in the presence of hydrogen gas did not contribute to further transformation of the FE pattern. Interrupting the hydrogen supply caused the formation of the "stage B" after a few seconds, following the process described in Section 3.2. The results demonstrate the reversible transformation of oxygen-induced FE patterns regardless of the initial stages of Pt-Rh specimen. The final, stable FE pattern is formed faster for reduction reaction in case of "stage A" than "stage $\mathrm{B}$ ", which is conditioned by the difference in the oxygen dose for which Pt-Rh surface was exposed: $3 \mathrm{~L}$ and $84 \mathrm{~L}$, respectively.

\section{Discussion}

Our studies provide an insight into elementary processes during catalytic reactions over Pt-Rh nanosized crystals under FEM imaging conditions. The results demonstrate the reversible transformation of oxygen-induced FE patterns 
Fig. 5 FE patterns of the Pt-Rh nanocrystal before and during $\mathrm{O}_{2}-\mathrm{H}_{2}$ reaction. (a) Field emission micrograph presenting the "stage B" before introduction of hydrogen. (b-d) Sequence of micrographs illustrating different stages during $\mathrm{O}_{2}-\mathrm{H}_{2}$ reaction triggered by $\mathrm{H}_{2}$ addition. Experimental conditions: $T=700 \mathrm{~K}, P_{\mathrm{O} 2}=3.7 \times 10^{-4} \mathrm{~Pa}$, $P_{\mathrm{H} 2}=3.0 \times 10^{-3} \mathrm{~Pa}$,

$F=2.3 \mathrm{~V} \cdot \mathrm{nm}^{-1}$
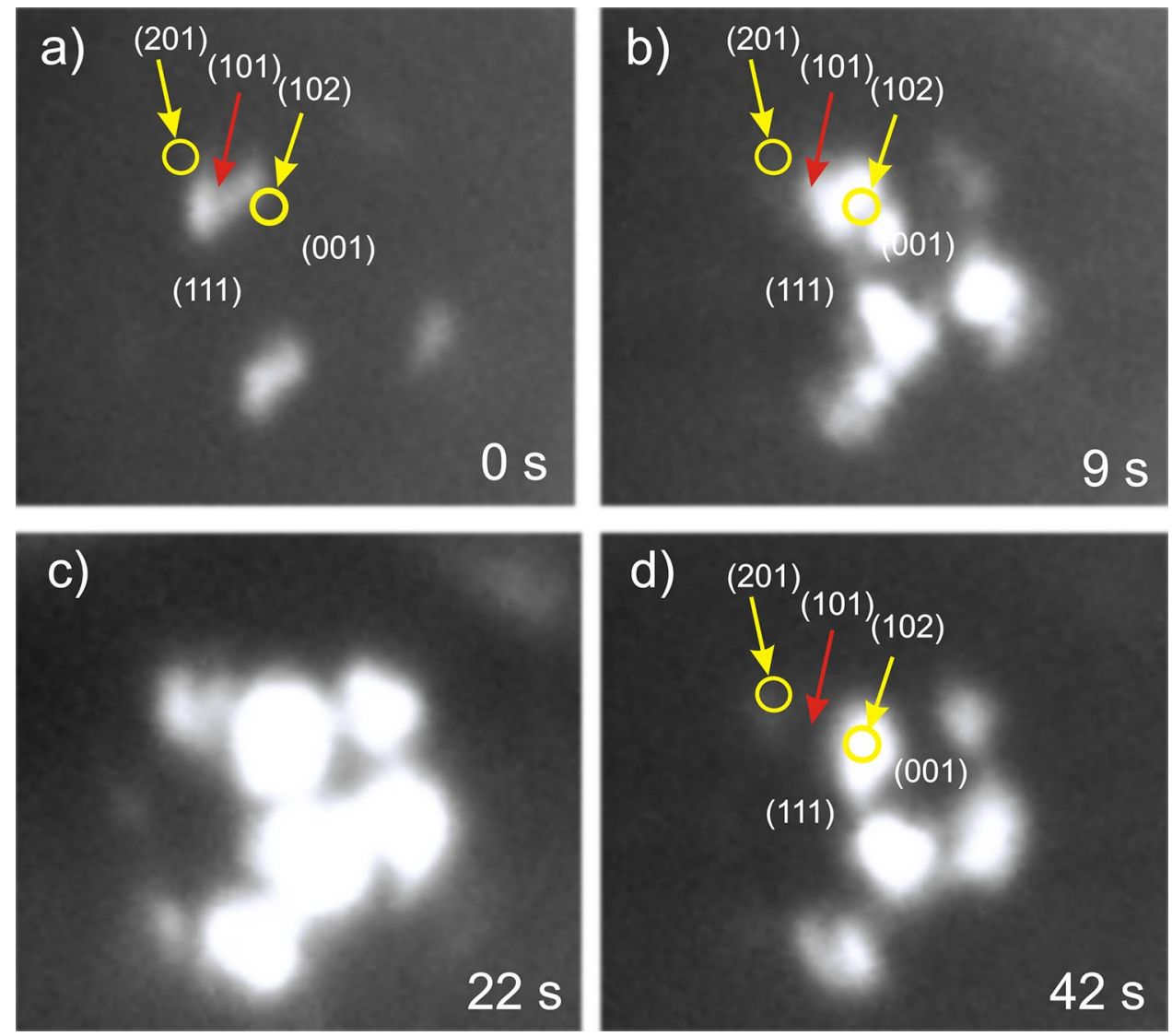

regardless of the initial stages of $\mathrm{Pt}-\mathrm{Rh}$ specimen under hydrogen-rich condition. In order to identify the causes leading to the FE pattern transformations encountered during $\mathrm{O}_{2}$ adsorption and reaction, the various processes were analyzed.

The presence of oxygen atoms on the metal and alloy surfaces, originating from the dissociative $\mathrm{O}_{2}$ adsorption, causes significant changes to their surface and bulk structure as well as their composition, through surface segregation of one component in multimetallic systems, various oxide species formation and/or surface reconstruction.

Previous studies showed that oxidation of $\mathrm{Pt}-\mathrm{Rh}$ alloy crystals caused a significant enrichment of their surfaces with $\mathrm{Rh}$ atoms [16-19]. The standard enthalpies of formation of the various $\mathrm{Pt}$ and $\mathrm{Rh}$ oxides species are $-134 \mathrm{~kJ} \cdot \mathrm{mol}^{-1}$ for $\mathrm{PtO}_{2},-71 \mathrm{~kJ} \cdot \mathrm{mol}^{-1}$ for $\mathrm{PtO}[25,26]$, -365 to $-405 \mathrm{~kJ} \cdot \mathrm{mol}^{-1}$ for $\mathrm{Rh}_{2} \mathrm{O}_{3}$ [27]. According to result obtained by APT, it was found that islands of $\mathrm{Rh}_{2} \mathrm{O}_{3}$ grow on the surfaces of the specimens due to migration of $\mathrm{Rh}$ atoms from the bulk to the surface [9]. Moreover, subsequent reduction of the oxidized specimens created core/shell structures consisting of a thin, almost pure, $\mathrm{Rh}$ layer at the surface, above a "core" with the bulk alloy composition.

Previous FEM results on the oxidation of Pt and Rh nanosized crystals revealed diminishing of emissivity of $\{012\}$ planes whereas the $\{113\}$ regions started to emit electrons intensively with oxygen adsorption [37-39]. A recently presented FE pattern of $\mathrm{Rh}$ emitter annealed in oxygen at $700 \mathrm{~K}$ was almost identical to that of "stage A" of Fig. 2d, with only $\{113\}$ regions visible as bright spots [38]. Similar FE patterns were also obtained for relatively early stages of Rh oxidation [37]. In the case of oxidation of Pt emitter tips, the FE patterns differ from those presented here, exhibiting also bright $\{011\}$ and $\{001\}$ planes [39]. Thus we suggest that our results at least do not exclude the expected $\mathrm{Rh}$ enrichment of $\mathrm{Pt}-\mathrm{Rh}$ crystal surface after $\mathrm{O}_{2}$ treatment, owing to the higher $\mathrm{Rh}-\mathrm{O}$ bond strength over $\mathrm{Pt}-\mathrm{O}$ [27]. However, it is clear that further APT experiments would be necessary to undoubtedly prove the Rh-enrichment in our samples.

It is well known that adsorption of oxygen on transition metal surfaces increases their work function $\phi$ considerably. As the density of field emission current exponentially depends on $\left(-\phi^{3 / 2}\right)$, this increase causes a strong decrease of FE pattern brightness. The observed decrease of total brightness of the FE pattern (Fig. 2e) can be attributed to dissociative adsorption of oxygen leading to $\mathrm{O}_{(\text {ads })}$ species at the surfaces of the field emitter. However, oxygen adsorption on the surfaces may and usually does cause a variety of other effects, like for instance local changes of the crystal planes (clock reconstructions [40], missing-row reconstructions 
[41]) and morphological transformations of the entire shape of the crystal $[42,43]$ that also have strong impact on local density of FE current. Oxygen adsorbed on the metal surface can as well diffuse under the surface. The existence of subsurface oxygen was observed for the platinum group metals, comprising Pt, Pd, Rh [44-51]. PEEM studies clearly attributed lowering of work function during oxygen adsorption on $\operatorname{Pt}(100)$ to subsurface oxygen diffusion [52]. All these effects affect the local electron emission of the field emitter. Thus correlated changes in brightness of planes in the FE pattern reported in Section 3.2., like decrease in brightness over $\{012\}$ planes accompanied by increase of brightness over $\{113\}$ regions, cannot be explained solely on the basis of FE patterns analysis.

In the study of adsorption of various gases on Rh field emitter tips [37], a model of parallel $\mathrm{O}_{(\mathrm{ads})}$ formation on $\{012\}$ planes and subsurface oxygen migration at $\{113\}$ was proposed to explain similar changes in FE patterns during oxygen adsorption. Direct proof of this model was provided in the latest work by Lambeets et al. [38], where combined FIM, FEM and APT techniques were used to study the oxidation of surfaces of Rh emitters. They found $\mathrm{Rh}\{113\}$ planes to act as portals for oxygen subsurface diffusion. Oxygen atoms diffuse from $\{012\}$ towards $\{113\}$ planes (and other planes along $\langle 0 \overline{2} 2\rangle$ zones) then diffuses into subsurface positions and accumulate beneath planes of this zone, especially $\{111\}$. As mentioned earlier, the field emission patterns for "stage A" are very similar to the pattern of oxidized Rh emitter presented in that work. Thus, it is reasonable to assume that the subsurface oxygen model is valid also in case of results presented here for Pt-Rh nanosized crystal. Oxygen atoms originating from the dissociative $\mathrm{O}_{2}$ adsorption migrate under the surface of $\{113\}$ planes and accumulate there. These oxygen atoms $\left(\mathrm{O}_{\text {(sub) }}\right)$ cause an inversion of the dipole momentum of the surface layer which decreases the local value of work function and promotes electron emission, making $\{113\}$ regions brighter in the emission pattern. The lowering of work function may be and likely is accompanied by morphological changes of the emitter surface induced by the $\mathrm{O}_{(\text {ads })}$ and $\mathrm{O}_{(\text {sub })}$ as well. However, based on the presented results, no reasonable pattern of these effects can be given. We believe that, at least, starting from formation of "stage A", the $\mathrm{O}_{\text {(sub) }}$ was present on the sample, and evolution of the emission patterns with oxygen exposure was at least partially induced by the diffusion and accumulation of $\mathrm{O}_{\text {(sub) }}$.

When hydrogen is co-adsorbed with oxygen on the $\mathrm{Pt}-\mathrm{Rh}$ sample, $\mathrm{H}_{2}$ molecules dissociate on the surface and $\mathrm{H}_{(\mathrm{ads})}$ come into reaction with $\mathrm{O}_{(\mathrm{ads})}$ to form water. At $700 \mathrm{~K}$, the so formed water molecules desorb rapidly from the surface of Pt-Rh crystal as they do in case of both Pt and Rh crystals. Previous experimental studies have demonstrated that the addition of the first $\mathrm{H}$ atom to chemisorbed oxygen is a relatively slow process while in comparison addition of a second $\mathrm{H}$ atom leading to $\mathrm{H}_{2} \mathrm{O}$ molecule production is fast [52-55]. It means that the lifetime of the $\mathrm{OH}_{(\mathrm{ads})}$ species is relatively short, i.e. $\tau \sim 10^{-10} \mathrm{~s}$ [55]. Molecularly adsorbed water causes a considerable decrease of $\boldsymbol{\phi}$. Therefore, the local brightening of the FE pattern during hydrogenation reactions is usually regarded to mark these regions of the field emitter, where the oxygen coverage decreases and water is being produced (and thus still present, despite the rapid desorption) on the surface. When the rate of the $\mathrm{H}_{(\mathrm{ads})}$ with $\mathrm{O}_{\text {(ads) }}$ reaction is higher than the rate of gaseous oxygen adsorption, the coverage of $\mathrm{O}_{(\mathrm{ads})}$ decreases locally, disturbing the equilibrium between $\mathrm{O}_{(\mathrm{ads})}$ and $\mathrm{O}_{(\mathrm{sub})}$, if the latest has been formed earlier. The chemical potential that keeps oxygen atoms in subsurface positions diminishes and $\mathrm{O}_{(\mathrm{sub})}$ atoms can diffuse back to the surface, where they react with hydrogen and subsequently desorb. When the diffusion of oxygen atoms from the subsurface to the surface, i.e. $\mathrm{O}_{(\text {sub })} \rightarrow \mathrm{O}_{(\text {ads }}$, is slower than the decrease of the oxygen coverage due to reaction with $\mathrm{H}_{(\mathrm{ads})}$, the brightness of the FE pattern increases slowly.

Note however, that several seconds after introduction of the hydrogen into the UHV system, the fast ("explosive") increase of local brightness of the FE pattern was observed. We believe that it refers to the ignition of fast and massive reaction of hydrogen atoms with oxygen atoms that diffuse from subsurface in large quantity. The combination of water desorption and subsequent formation of empty sites results in a sharp increase in brightness. This sharp increase of empty sites on the surface facilitates the net mobility of oxygen atoms from the subsurface reservoir towards the surface. The question of the direct reason for such impressive rise of the emission current density arises. First, it may be explained by the deep drop of the local work function due to massive water production. If the water synthesis reaction rate is comparable to water desorption rate, a transient population of surface water molecules exists. When the flux of oxygen atoms from subsurface decreases in time, the reaction rate and thus concentration of water on the surface falls down, which leads to darkening of the FE pattern. Finally, when there is no subsurface oxygen available, the hydrogenation reaction involves only oxygen that adsorbed from gaseous phase and then dissociated. The water synthesis is limited by supply of oxygen from gaseous phase, thus there is very limited amount of water on the surface, as desorption rate is high at $700 \mathrm{~K}$. The FE patterns stabilize over time as reaction flows, finally highly resembling the pattern of a clean emitter. This suggests that any structural and/or morphological changes on the Pt-Rh crystal caused by oxygen adsorption and oxygen subsurface accumulation disappear. 
The temperature during the experiments $(700 \mathrm{~K})$ allows the surface to transform back into its original state that is observed.

As already mentioned, when all oxygen is removed from subsurface layers, continued co-adsorption of oxygen and hydrogen does not contribute to further transformation of the FE pattern, and the $\{012\}$ facets remain steadily active under constant reaction conditions. It indicates that co-adsorption of hydrogen prevents formation of the subsurface oxygen, at least under the hydrogen-rich conditions of our experiments. When hydrogen was removed from the chamber, the re-evolution of the FE pattern was observed, as it was described in Section 3.2. This fact may be an argument towards a kinetic blocking effect by $\mathrm{H}_{(\text {ads }}$ on the formation of $\mathrm{O}_{(\text {(sub) }}$. Moreover, the $\{012\}$ facets exhibit a significant catalytic activity, which is a good indication of their activity in the reduction reaction of $\mathrm{O}_{2}-\mathrm{H}_{2}$.

\section{Conclusions}

In this work, the oxygen adsorption and its reaction with hydrogen were investigated on Pt-Rh nanosized crystals at $700 \mathrm{~K}$ by Field Emission Microscopy. The results provide insights on the reactivity and stability of bimetallic alloy catalysts during the very first stage of oxidation processes. Interaction of chemisorbed oxygen atoms with the Pt-Rh crystal surface results in the formation of subsurface oxygen which induces changes in the work function distribution over the crystal surface and/or the surface morphology. Initially, for relatively low exposures of $\mathrm{O}_{2}$, subsurface sites are filled by oxygen atoms beneath the $\{113\}$ planes. With increasing amounts of oxygen atoms, the progressive surface transformation of the nanocrystal surface takes place. The subsurface oxygen causes further evolution of the composition of the very first layers of the crystal, as observed in the FE patterns. Subsequent reduction of specimens re-established the original field emission pattern, where only $\{012\}$ planes were clearly visible. The results seem to confirm the expected Rh enrichment of Pt-Rh crystal surface after $\mathrm{O}_{2}$ treatment.

From a more general point of view, this study also highlights the importance in pre-treatment/activation steps in the catalytic reactivity of bimetallic alloys. This is of great importance for industrial applications of catalysts since the reactivity of alloys is affected by surface reconstructions, surface enrichments, and modifications of the chemical nature of the very first atomic layers. Further work with the use of APT technique should address the extent of surface segregation during the ongoing reaction to correlate the composition with the structure and the reactivity of such catalysts.
Acknowledgments S.O., R.B., C.B. and T.V.d.B. thank WalloniaBrussels International for the Bilateral Cooperation Agreement and the Bilateral Cooperation between the Fonds de la Recherche Scientifique (F.R.S.-FNRS) and the Polish Academy of Sciences (PAN). S.V.L. is grateful for the support of the Linus Pauling Distinguished Postdoctoral Fellowship program at PNNL and for the financial support of the Fonds de la Recherche Scientifique (F.R.S.-FNRS) (FRIA PhD Grant). C.B. thank the Fonds de la Recherche Scientifique (F.R.S.-FNRS) for financial support (Postdoctoral fellowship from FNRS). This work was supported by research grant from University of Wrocław (no. 1425/M/ FD/15).

Authors' contribution Investigation: Sylwia Owczarek, Sten V. Lambeets; Writing - original draft: Sylwia Owczarek, Robert Bryl; Writing - review \& editing: Sten V. Lambeets, Cédric Barroo, Leszek Markowski, Thierry Visart de Bocarmé; Support to investigation: Olivier Croquet; Funding acquisition: Thierry Visart de Bocarmé; Supervision: Thierry Visart de Bocarmé.

\section{Declarations}

Funding This work was supported by a research grant from University of Wrocław (no. 1425/M/FD/15); a Bilateral Cooperation Agreement from Wallonia-Brussels International (WBI); a Bilateral Cooperation between the Fonds de la Recherche Scientifique (F.R.S.-FNRS) and the Polish Academy of Sciences (PAN); and the Fonds de la Recherche Scientifique (F.R.S.-FNRS). S.V.L. acknowledges the Linus Pauling Distinguished Postdoctoral Fellowship program at PNNL for financial support.

Conflict of interest The authors declare no competing interests.

Availability of data and material Data is available upon reasonable request.

Code availability Not applicable.

Open Access This article is licensed under a Creative Commons Attribution 4.0 International License, which permits use, sharing, adaptation, distribution and reproduction in any medium or format, as long as you give appropriate credit to the original author(s) and the source, provide a link to the Creative Commons licence, and indicate if changes were made. The images or other third party material in this article are included in the article's Creative Commons licence, unless indicated otherwise in a credit line to the material. If material is not included in the article's Creative Commons licence and your intended use is not permitted by statutory regulation or exceeds the permitted use, you will need to obtain permission directly from the copyright holder. To view a copy of this licence, visit http://creativecommons.org/licenses/by/4.0/.

\section{References}

1. Weiting Y, Porosoff MD, Chen JG (2012) Chem Rev 112:5780-5817

2. Markovic NM, Schmidt TJ, Stamenkovic V, Ross PN (2001) Fuel Cells 1:105-116

3. Shelef M, Graham GW (1994) Catal Rev Sci Eng 36:433-457

4. Slinko M, Fink T, Löher T, Madden HH, Lombardo SJ, Imbihl R, Ertl G (1992) Surf Sci 264:157-170

5. Lombardo SJ, Fink T, Imbihl R (1993) J Chem Phys 98:5526-5539 
6. Fink T, Dath JP, Imbihl R, Ertl G (1991) J Chem Phys 95:2109-2126

7. Contour JP, Mouvier GJ (1977) J Catal 48:217-228

8. Li T, Bagot PAJ, Marquis EA, Tsang SCE, Smith GDW (2012) J Phys Chem C 116:4760-4766

9. Li T, Marquis EA, Bagot PAJ, Tsang SC, Smith GDW (2011) Catal Today 175:552-557

10. Bergene E, Tronstad O, Holmen A (1996) J Catal 60:141-147

11. Hebenstreit ELD, Hebenstreit W, Schmid M, Varga P (1999) Surf Sci 411:441-453

12. Van Delft FCMJM, Van Langeveld AD, Nieuwenhuys BE (1987) Surf Sci 189/190:1129-1134

13. Platzgummer E, Sporn M, Koller R, Forsthuber S, Schmid M, Hofer W, Varga P (1999) Surf Sci 419:236-248

14. Beck DD, DiMaggio CL, Fisher GB (1993) Surf Sci 297:293-302

15. Wouda PT, Nieuwenhuys BE, Schmid M, Varga P (1996) Surf Sci 359:17-22

16. Ren DM, Qin HG, Wang JB, Tsong TT (1993) Phys Rev B 47:3944-3946

17. Athenstaedt W, Leisch M (1996) Appl Surf Sci 94(95):403-408

18. Beck DD, DiMaggio CL, Fisher GB (1993) Surf Sci 297:303-311

19. Bagot PAJ, Kreuzer HJ, Cerezo A, Smith GDW (2011) Surf Sci 605:1541-1546

20. Bagot PAJ, Cerezo A, Smith GDW (2007) Surf Sci 601:2245-2255

21. Barroo C, De Decker Y, Jacobs L, Visart de Bocarmé T (2017) Appl Surf Sci 412:564-570

22. Barroo C, De Decker Y, Visart de Bocarmé T, Gaspard P (2015) J Phys Chem Lett 6:2189-2193

23. Barroo C, De Decker Y, Visart de Bocarmé T, Kruse N (2016) Phys Rev Lett 11:144501

24. Barroo C, De Decker Y, Visart de Bocarmé T (2017) J Phys Chem C 121:17235-17243

25. Nagano YJ (2002) Therm Anal Cal 69:831-839

26. Samsonov GV (1982) The oxide handbook, 2nd edn. Plenum Publishing Corporation, New York

27. Jacob KT, Uda T, Okabe TH, Waseda Y (2000) High Temp Mater Process 19:11-16

28. Barroo C, Gilis N, Lambeets SV, Devred F, Visart de Bocarmé T (2014) Appl Surf Sci 304:2-10

29. Kruse N, Visart de Bocarmé T (2008) Heterogeneous catalysis and high electric fields. In: Ertl G, Knözinger H, Schüth F, Weitkamp J (eds) Handbook of heterogeneous catalysis, 2nd edn. Wiley-VCH Verlag GmbH \& Co. KGaA, Weinheim, pp 870-895

30. Müller EW, Tsong TT (1969) Field ion microscopy: principles and applications. Elsevier, New York

31. Fowler RH, Nordheim L (1928) Proc R Soc Lond Ser A 119:173-181
32. Kawano H (2008) Prog Surf Sci 83:1-165

33. Derry GN, Ross PN (1985) J Chem Phys 82:2772-2778

34. Barroo C, Lambeets SV, Devred F, Chau TD, Kruse N, De Decker Y, Visart de Bocarmé T (2014) New J Chem 38:2090-2097

35. McEwen JS, Gaspard P, De Decker Y, Barroo C, Visart de Bocarmé T, Kruse N (2010) Langmuir 26:16381-16391

36. Vanselow R, Li XQD (1992) Surf Sci 264(1-2):L200-L206

37. Lambeets SV, Barroo C, Owczarek S, Jacobs L, Genty E, Gilis N, Kruse N, Visart de Bocarmé T (2017) J Phys Chem C 121:16238-16249

38. Lambeets SV, Visart de Bocarmé T, Perea DE, Kruse N (2020) J Phys Chem Lett 11:3144-3151

39. Owczarek S, Lambeets SV, Barroo C, Bryl R, Markowski L, Visart de Bocarmé T (2018) Top Catal 61(12-13):1313-1322

40. Alfè D, de Gironcoli S, Baroni S (1999) Surf Sci 437:18-28

41. Medvedev VK, Suchorski Y, Voss C, Visart de Bocarmé T, Bär T, Kruse N (1998) Langmuir 14:6151-6157

42. Bryl R, Olewicz T, Visart de Bocarmé T, Kruse N (2010) J Phys Chem C 114:2220-2226

43. Bryl R, Olewicz T, Visart de Bocarmé T, Kruse N (2011) J Phys Chem C 115:2761-2768

44. Hesse M, Günther S, Locatelli A, Menteş TO, Santos B, Imbihl R (2016) J Phys Chem C 120:26864-26872

45. Wei H, Lilienkamp G, Imbihl R (2007) J Chem Phys 127:024703

46. Oertzen A, Mikhailov AS, Rotermund HH, Ertl G (1997) J Phys Chem B 102:4966-4981

47. Auguilar-Hidalgo D, Lemos MC, Córdoba A (2013) Surf Sci 607:203-211

48. McMillan N, Lele T, Snively C, Lauterbach J (2005) Catal Today 105:244-253

49. Rebholz M, Prins R, Kruse N (1992) Surf Sci 269/270:293-299

50. Ganduglia-Pirovano MV, Reuter K, Scheffler M (2002) Phys Rev B 65:245426

51. Ladas S, Imbihl R, Ertl G (1989) Surf Sci 219:88-106

52. Wagner ML, Schmidt LD (1995) J Chem Phys 99:805

53. Klikovits J, Schmid M, Gustafson J, Mikklsen A, Resta A, Lundgren E, Andersen JN, Varga P (2006) J Phys Chem B 110:9966

54. Wike S, Natoli V, Cohen MH (2000) J Chem Phys 112:9986-9995

55. Africh C, Esch F, Li WX, Corso M, Hammer B, Rosei R, Comelli G (2004) Phys Rev Lett 93:126104

Publisher's Note Springer Nature remains neutral with regard to jurisdictional claims in published maps and institutional affiliations. 